\title{
TRAFFIC AND TRANSPORTATION
}

John Rannells $\dagger$

Traffic congestion is as old as cities; a quiet and uncrowded market place is no proper market place at all. Transport within and among urban centers is always most valued when most heavy; a broad highway or commercial street that is rarely busy with traffic is just a waste of resources.

The basic problem of traffic and transportation is always the same-to balance the seesaw of needs and facilities. The present difficulty in urban areas is that existing streets and highways and rail facilities no longer match the new demands created by recent population growth and new location patterns of economic activity. The dominant driving force in metropolitan growth is sheer increase in population and industrial production, but the future shape of urban areas is determined by the fact that nearly all of the increase occurs in the suburbs and takes place mainly as a filling-in of the spaces between the older suburban clusterings along rail lines and main highways.

\section{Population Shifts}

The general picture is much the same in all cities. More than half of the country's population-fifty-nine per cent in 1955-is concentrated in the Standard Metropolitan Areas and nearly all of the growth from 1950 to 1955 (97 per cent) has occurred in these SMA's. ${ }^{1}$ Not much of this increase (only 16 per cent) was located in the central cities but these still dominate, with well over half of the total SMA population. Growth outside the central cities is divided rather evenly between the close-in and outer fringe areas (urban fringe, 38.3 per cent; rural fringe, 43.1 per cent). These provide the "growing room" for the metropolitan areas of the future. Outside of the SMA's, the rural population is actually decreasing, although the urban populationrepresenting the smaller, scattered cities-is increasing at a fair rate, more rapidly indeed than are the central cities.

The population trends are shown in the accompanying table. Continuation to 1975 would shift the balance further toward the SMA's

$\dagger$ Assistant Director, City of Philadelphia Urban Traffic and Transportation Board; Member, American Society of Civil Engineers; Associate Member, American Institute of Architects. B.C.E., 1924, Ohio State University; M.S. in City Planning, 1951, Columbia University.

1. Urbanized areas, consisting of counties or groups of counties containing at least one city with 50,000 inhabitants. 
(69 per cent of total population in 1975 compared with 59 per cent in 1955), but the central cities would then have only forty per cent of total SMA population (compared with 53.6 per cent in 1955). The total urban-rural balance does not change much; the great change is in the metropolitan fringes.

蒸
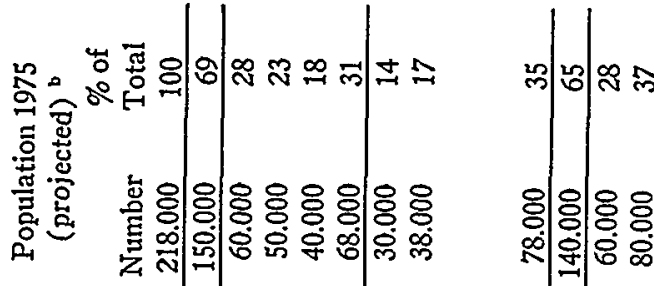

密

$\frac{2}{2}$

is

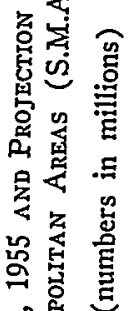

突

«

岁要 영

잉 융응

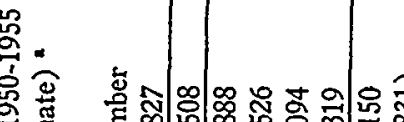

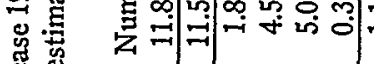

过

密

E

总

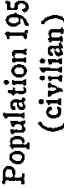

\section{हึ.}

se

岂

ஜิษ

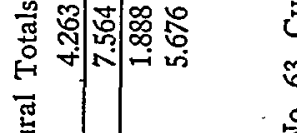

Ð

온

응

营 8

可

을 ญ

贾

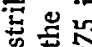

ํㅜㅇㅇㅛ

.

กิ

นू.

$\exists$

낭ㅎㄴ

둔 훈

思

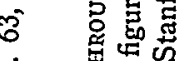

号

กิ ஸें

ث⿺辶一兀

虫.

늘

s

$\therefore$

을

曾

䆛

내용

年

열 员

它兽

客

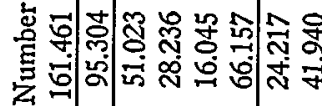

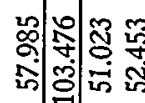

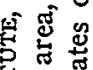

㝵㟧

管

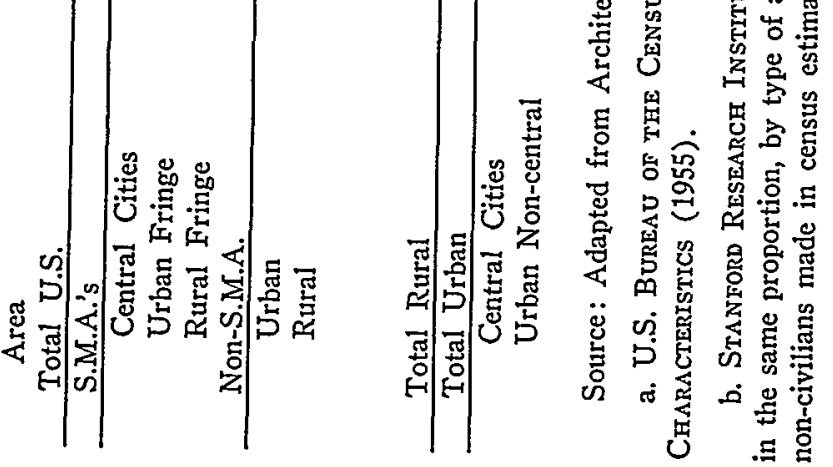


Against this general background, the detailed picture of population in each metropolitan area-shaped by local economic geography and history of development-is seen in terms of size, age, density and rates of growth of the central city, its satellite cities and accessory suburban areas. In some of the older metropolitan areas, the central city is "full-up" and all of the increase will occur in the suburbs. In all cases, the new growth tends to be outward, at low densities, but the total shape of future development is strongly determined by the existing major centers of employment and their relation to population distribution. In the older, larger metropolitan areas, the main business districts of the central city and the satellite cities are so large that they continue to dominate the picture even though most of the new growth is dispersed.

\section{Transportation Networks}

The physical framework of each metropolitan region consists of the main lines of transport, both highway and rail, that have developed concurrently with the growth of the urban centers. Lacing together the entire pattern of urban development is a mesh of roads and streets and minor rail lines. On a map of the region, the transportation problem is outlined by these connective networks, together with the activities served by them, seen as density distributions of people's activities that make up the social and economic life of the region. Out of the many distributions that could be mapped, those showing population and employment are the most pertinent to the problem of providing transportation facilities to meet future needs, for it is the journey to work, increasingly by private automobile, that puts the great overload on our network of highways and arterial streets. The handling of goods, whether by rail or highway, is a large fraction of the transportation problem, but the rail networks are already fixed and truck movements are rather well distributed over the highway network. They are not a major factor in peak-hour congestion, except in limited areas.

Until recent years the facilities for transportation have developed at a pace fairly commensurate with the need for them but never at an even pace. Sometimes the facilities anticipated the need. This was frequently the case with mass transit-railroad commuter lines and electric interurban or streetcar lines-constructed into undeveloped areas which promptly "boomed." Sometimes the needs were overfulfilled, as in the construction of a grand boulevard or the laying down of more streetcar lines than the traffic would support. But this was all before the general development of hard-surfaced highways and the almost universal use of the private automobile which, in turn, has 
enforced the demand for a closed-spaced network of paved roads and streets.

Today, the need for improved streets and highways has far outrun existing capacities. The situation is particularly acute in urban areas where floods of automobiles have overburdened city streets that served well enough as highways a generation ago. The shift to private automobiles in recent years has rendered mass transit uneconomical, leading to a worsening of transit service and further congestion of streets.

Highway construction in open country between cities is well in hand, its technical problems fully mastered by highway engineers. But provision of major highways and arterial streets in urban areas has fallen far behind the need for them, so far behind that the very institutions-units of state and local government-which have been providing the streets and highways, now find themselves unable to function effectively in a situation that has become regional in scope.

In this situation an improvement program geared to present needs can never catch up. It is necessary to devise a highway network which will meet future needs, together with a flexible construction program that can be kept in pace with metropolitan growth. But this must be worked out for the metropolis as a whole and in sufficient detail to serve local needs in every part of it. The potential capacities of existing left to the state, concerned as it is with only the main skeletal network facilities must be utilized to the full, if expenditures are to be kept within bounds. Such a program cannot be pieced together out of fragments devised by the separate units of local government, nor can it be of through highways. It must be worked out by an agency which is equipped to deal on a regional basis with all phases of the problem.

\section{Scope of the Metropolitan Transportation Problem}

Transportation provides vital connections between the many functioning parts of the metropolitan organism, parts divided by political boundaries that have no reference to the transportation services being performed. Solution of transportation problems on a metropolitan scale must encompass all the types of geographical areas that are served, with their different kinds and degrees of development, and all the modes of transportation that are used to provide the necessary services.

By far the most important. area, most intensely developed and generator of the heaviest movements of persons and very heavy movements of goods, is the central business district ( $\mathrm{CBD}$ ), the commercial and administrative core of the region. ${ }^{2}$ It is the oldest part of the city,

2. A considerably larger area than the most intensely developed commercial core of large buildings is covered by the CBD. In New York, for example, all of Manhattan below 59th Street is included. 
with many vestiges of its earlier development, including old residential areas, some surviving but most of them continually being converted to commercial uses, and old central manufacturing and wholesaling areas in a continual state of change, usually leading to blight or to renewal for other types of use, commercial or residential-almost invariably high-rent or public-housing, rarely middle-income.

The CBD is the heart and headquarters of the city and the region, the major focus of all transportation networks, yet it is orphaned politically. Its resident population is small, divided between wealthy and poor. Its most influential citizens-business executives, professionals, industrialists-usually reside in the suburbs, even outside of the city altogether.

Closely bordering the CBD (but with no clear line of demarcation) is an area of relatively intense development, residential, industrial, commercial, extending outward in different directions from the center into more scattered areas of dense industrial development, small business and retail trade centers and new shopping centers. These "urban dense" areas occur throughout the city and nearby suburbs; they generate heavy traffic themselves and are traversed by traffic generated by the city center or traffic which is trying to avoid central congestion. The urban transportation problem is most intense and difficult to solve in these areas of high concentration, areas which often extend far beyond the central city into neighboring jurisdictions.

Due to its density, the CBD is the most costly area in which to construct the limited-access highways that have become essential to metropolitan development. Costs in the densely urbanized environs of the city are also very high, far beyond the scale of expenditure that has been current in all but a few metropolitan areas. Highway programs for the outer suburban and rural areas partake more of the intercity patterns, where needs are not so crucial as in the main centers of population and industrial and commercial activity.

The need for superhighways in central areas is brought to the fore by the Federal Highway Bill of $1956,{ }^{3}$ which allows for ninety per cent of the construction cost of projects that form parts of the National System of Interstate and Defense Highways to be paid out of federal funds. This "interstate system" connects and penetrates all major cities, serving local needs as well as interstate traffic. Revisions to the system, designated in September 1955, provide additional access and bypass routes in urban areas. The entire interstate system is to be brought up to the highest standards of capacity, speed and safety,

3. 70 STAT. 374, 23 U.S.C.A. \$151 (Supp. 1956). 
equivalent to the latest toll roads. These standards, backed by the high allocation of federal funds, will dominate the urban transportation scene for years to come. $::$

Important as the interstate system is, it does not provide the full quota of urban expressways that is needed, but it does give a strong impetus by providing a substantial high-quality fraction of the complete network. And it may exert a powerful force toward dealing with transportation on a regional basis and entering on a long-range program for developing an integrated up-to-date system of expressways and arterial streets, which can keep pace with future metropolitan growth.

Criteria established by the United States Bureau of Public Roads for selection of urban portions of interstate-system routes may be used as a guide for planning all urban expressways. The following quotations are taken from an official listing of these criteria : ${ }^{4}$

"At the approaches to cities, and particularly the larger cities, a very large part of the traffic on the interstate system orginates in or is destined to the city itself. Distributing routes within cities should be provided in addition to circumferential routes which serve to by-pass the traffic that is not destined for the city. . . .

"Routes which avoid the business centers of cities are needed to serve traffic bound to or from points other than the center of the city. Such routes may be so located as to serve both as arteries for through traffic around the city between various approach highways and as distribution routes for the movement of traffic with local origins and destinations to and from the various quarters of the city. . . . At many of the relatively large cities, the need is for routes completely encircling the city. In some of the larger cities a belt route near the central business district may be needed in addition to an outer circumferential route. . . .

"Railway terminals, both passenger and freight, wharves and docks, and airports generate large volumes of street and highway traffic associated with the essential interchanges between the several modes of transportation. The location of the interstate system routes at cities should be so placed as to give convenient express service to these various major traffic-generating locations within and in the vicinity of cities and also to the business center of the city and main industrial areas. The location of the interstate system should permit and encourage a desirable coordination of highway transportation with rail, water and air transportation. . . .

4. Statement by Commissioner of Public Roads C.D. Curtis, submitted to the Subcommittee on Roads of the Senate Committee on Public Works, April 15, 1955. 
"Interstate system routes will provide for only a small portion of the movement of traffic in most cities. The routes should be located and designed to be an integral part of the entire urban transportation plan."

The above statement of criteria could apply only to a comprehensive system of expressways, designed to serve the whole metropolitan area. Such an expressway network cannot function effectively, however, without adequate connections to every part of the road and street network. Design and construction of the expressways is generally undertaken by the state in collaboration with the affected units of local government, but the latter are left to deal as best they can with local problems of traffic congestion. Thus in the usual organization of government units there is no instrument for dealing with the whole problem of automotive transport on a regional basis.

Any regional approach to transportation problems will have to take account of all modes: not only the use of highways and streets by truck and automobile and public transit, but also the terminal problem in the city center, which involves parking and local distribution and management of street traffic. Mass transit is particularly important in providing economical transportation of people; its enhancement would tend to cut expenditures for highways. Railroads must also be taken into account in relation to freight distribution (both direct and in combination with trucks) and commuter service (which can greatly relieve the need for radial expressways).

Public appreciation of the need for a regional solution is generally lacking, perhaps no more so in suburban areas than in the central city. The need for change, however, may be more apparent in the latter where decay is increasingly evident. As lines of political jurisdiction are crossed, varying pressures are exerted, all more or less parochial. The "interest" groups-railroad, mass transit, trucking, automobile users, all more inclined to compete than co-operate-also have their overlapping jurisdictions in which varying degrees of public control are applied. In none of these areas, neither political nor technological, is there enough drive toward a regional solution to make it effective. The problem defines itself in regional terms; its solution will require collaboration among all sorts of transportation agencies and political units.

\section{Organizing for Metropolitan Transportation}

Provision of transportation facilities to accommodate future requirements must be based on the best possible forecasts of future population and economic activities and the distributions of these 
throughout the metropolitan region. The facilities actually provided will affect, in turn, the relative growth of different parts of the region. Indeed, the appropriateness of these facilities to future demands and their scale and programming may be determining factors in the sharpening competition among metropolitan areas. Within the next few years, those cities which do not have ready access to their major centers of activity will find themselves left behind in the race for economic growth.

In some larger urban areas, major services are supplied by public bodies: mass transit in Boston, New York, Cleveland, Chicago and elsewhere; toll bridges and tunnels in New York outstandingly; turnpikes or toll parkways in several eastern states; terminals in many cities, from parking and bus to airports and marine. Any of these agencies could become an important factor in the development of a regional system of facilities, but each of them is devoted to the enhancement of its own operation and tends to become a "vested interest" in its own field. The impetus for regional solutions of the total transportation problem will have to come from civic groups.

Our entire metropolitan population-and this includes those who have sought escape from city congestion in the urban fringes-is faced repeatedly with decisions which will affect the qualities and satisfactions to be achieved in every part of each metropolitan area. The future desirability of each metropolis will depend in large measure on the goals for development which guide these decisions and the extent to which the well-being of the region as a whole is the guiding principle.

Competent handling of urban traffic of all kinds by the existing agencies, both public and private, can make a considerable beginning toward healthy regional development, but the full achievement will require planning on a regional basis for both the facilities to be built and the land uses to be served. This conclusion follows the analysis of urban traffic problems by Mitchell and Rapkin at three levels:

". . . First and most immediate in every city is the regulation and control of traffic within given channels of movement that serve a given pattern of land use. . . . The second ... is the provision and improvement of physical channels of movement, such as highways and public transit lines. . . . This level of action is both urgent and expensive.

. . The third and most basic level of action for a long-run solution of traffic problems is the planning, guidance, and control of change in the pattern of land uses in the interest of effciency.

5. Mitchell \& Rapkin, Urban Traffic-A Function of Land Use 6-7 (1954). A further development of the land-use approach to urban problems will be found in Rannells, The Core of the City (1956). 
Work at the first level is the constant concern of officials and public alike. Much can be done here, by collaboration among existing agencies, to improve present conditions and even to postpone capital improvements for a time. But no long-run solution is to be expected without new construction, and work at this level will continue regardless of the scale of future improvements.

Accomplishments at the second level will reveal choices made between immediate and long-range objectives-between parochial pressures or obvious needs of separate transportation agencies on the one hand and the desired development of the entire metropolis on the other. These choices will never be clear-cut, for the local or special interests are bound up with the good of the whole region and will influence any realistic development plan for the region.

A major decision confronting the community is whether to ride along with the "natural" development (or decay in some instances) of transportation facilities or to devise a plan for the future and to develop an organization for putting it into effect. The most effective organization will be representative of government at all levels and will utilize existing facilities to the full. The best achievable comprehensive development plan will be a consensus of agreed-on conclusions, shared in by the various political subdivisions and transportation agencies of various kinds-public carriers, toll-collecting authorities and agencies of state and local government.

An outstanding example of the comprehensive approach to metropolitan transportation problems may be seen in the work of Philadelphia's Urban Traffic and Transportation Board, appointed early in 1954, its members deliberately selected to include responsible representatives of transportation interests-railroad, transit, motor-club, taxicabs, trucking, mercantile, investment banking and so forth.

Early in its deliberations, the Board concluded that Philadelphia's transportation problems extend far beyond the city's boundaries and must be tackled on a regional basis, that all modes of transportation must be included and a balance struck between rapid transit and express highway facilities. The full "Conclusions and Recommendations" of the Board are published in its Plan and Program 1955 along with an extensive "Report of Staff" on which these conclusions are largely based.

The capital cost of improvements proposed by the Board over a twenty-five-year period is about 1.6 billion dollars for the Philadelphia metropolitan area (five counties in Pennsylvania and three in New Jersey). This is an enormous sum, but even more startling is the current expenditure for all forms of transportation services in this 
area, amounting to 1.4 billion dollars per year. This huge annual outlay does not provide good and efficient transportation service because too much is being spent for operation of vehicles and too little for the facilities on which effective and economical operation is possible.

In order to develop and administer a comprehensive transportation system, the Board recommended an early creation of a regional transportation organization, embracing the eight counties and vested with the necessary powers. Such a regional agency should be directed by a council which is truly representative of the people and the localities of the region. A majority of this council's members should be elected directly by the voters.

The establishment of such a politically responsible regional organization is beset with difficulties. Meanwhile Philadelphia deals with its transportation problems within the regular framework of city departments, but with the advice of a newly-constituted Urban Traffic and Transportation Board made up of city officials and citizen members not having direct interest in transportation.

The usefulness of the regional approach has been demonstrated recently in several cities by comprehensive surveys leading to design of major new transportation facilities. Rapid transit systems were designed for the San Francisco Bay area and for the South Jersey area tributary to the Philadelphia-Camden Bridge. ${ }^{6}$ Future highway development was taken into account in both these studies, as well as future patterns of land use that would result from construction of the transit lines. Determination of expressway needs for the metropolitan area is the main purpose of a recent study in Detroit ${ }^{7}$ and a current study in Chicago. In both of these, relationships between transportation facilities and land uses are given very close study; in Chicago, a close analysis of the balance between transit and highway use is being undertaken for the first time.

The results of these large-scale surveys-costing sometimes a million dollars and more-are not to be taken on faith. Their design recommendations may be a reflection of past trends or they may represent a consultant's conviction that only "the best" solution is worth building, regardless of cost and without regard for economic balance between highway and mass-transit development. The highly-developed

6. Parsons, Brinckerhoff, Hall \& MacDonald, Regional Rapid Transt, A Report to the San Francisco Bay Area Rapid Transit Commission (1955); Parsons, Brinckermoff, Hall \& MaCDonald, Southern New Jersey Mass Transportation Survey (1956). The latter survey was made for the Delaware River Port Authority of Pennsylvania and New Jersey.

7. Mrchigan State Hrghway Departament, Report on the Detroit Metropolitan AREA TRAFFic Study (vol. 1: Data Summary and Interpretation 1955; vol. 2: Future Traffic and a Long-range Expressway Plan 1956). 
techniques for analyzing relationships between improved facilities and land-use changes may crank out recommendations on the high-speed electronic computers which confirm undesirable patterns of land uses or call for expenditures beyond the economic strength of the community to support.

The comprehensive transportation survey is a powerful tool for planning the future metropolis. To be effective in the long run, the results must be kept up to date periodically by a continuing organization which can modify development programs as conditions change. The idea to be kept always in mind is that transportation facilities can be a major force for developing the kind of region that its citizens wish to live in, and that the results will reflect the citizens' choice of goals. 